\title{
Desafios e possibilidades para a Educação (Matemática) em tempos de "Covid-19" numa escola em crise
}

\section{Challenges and possibilities for Education (Mathematics) in times of "Covid-19" in a school in crisis}

\author{
Carolina Tamayo ${ }^{1}$ \\ Michela Tuchapesk da Silva ${ }^{2}$
}

\begin{abstract}
Resumo:
Este artigo parte da concepção de uma escola em crise que agudizada em tempos da pandemia provocada pelo vírus "Covid-19" tem gerado diversos desafios para a Educação (Matemática) no Brasil, especialmente após a divulgação das Diretrizes para escolas durante a pandemia publicadas pelo Ministério da Educação que autorizaram as escolas a desenvolverem atividades de ensino de forma remota. Partimos de alguns estudiosos que associam esta crise da educação escolar ao esgotamento do chamado projeto da Modernidade/Colonialidade, em prol de pensar uma Educação (Matemática) que não se subjuga a ele, mas que, a partir de movimentos de desobediência político-epistêmica estuda os conhecimentos matemáticos vinculados a outras cosmogonias não ocidentais. Para isto, apresentaremos falas de crianças, jovens e famílias, assim como imagens relacionadas aos problemas e dilemas da educação nesta pandemia, que colocaram-se em circulação pelas mídias e redes sociais eletrônicas após o início do isolamento social e do fechamento das escolas públicas da Educação Básica, procurando tensionar e pensar de modos outros os desafios e possibilidades da Educação (Matemática) em tempos de uma vida outra provocada pelo efeitos do "Covid-19".
\end{abstract}

Palavras-Chave: Etnomatemática; Modernidade/Colonialidade; Decolonialidade; Justiça Social. Racismo Estructural.

\section{Resumen:}

Este artículo parte de la concepción de una escuela en crisis que empeoró en tiempos de la pandemia causada por el virus "Covid-19" y que ha creado varios desafíos para la Educación (Matemática) en Brasil, especialmente después de la publicación de las Directrices para las escuelas durante la pandemia, publicadas por el Ministerio de Educación, que autorizó a las escuelas para desarrollar actividades de enseñanza de forma remota. Partimos de algunos académicos que asocian esta crisis de la educación escolar con el agotamiento del llamado proyecto Modernidad/Colonialidad, para pensar en una Educación (Matemática) que no esté subyugada a él, sino que, basada en movimientos de desobediencia políticoepistémica, estudie los conocimientos matemáticos vinculados a otras cosmogonías no occidentales. Para ello, presentaremos discursos de niños, jóvenes y familias, así como imágenes relacionadas con los problemas y dilemas de la educación en esta pandemia, que se distribuyeron a través de los medios de comunicación y las redes sociales electrónicas después del comienzo del aislamiento social y el cierre de las escuelas públicas de Educación Básica, procurando tensionar y pensar de diferentes maneras los desafíos y posibilidades de la Educación (Matemática) en tiempos de una vida diferente causada por los efectos del "Covid-19".

\footnotetext{
${ }^{1}$ Doutora em Educação pela Universidade Estadual de Campinas. Professora da Faculdade de Educação da Universidade Federal de Minas Gerais (Brasil) e integrante do grupo de pesquisa interinstitucional inSURgir da mesma universidade. Integrante dos grupos de pesquisa "Educação, Linguagem e Práticas Culturais" da UNICAMP e do grupo "Matemática, Educación y Sociedad" da Universidad de Antioquia (Colômbia). Coordenadora para América do Sul da Red Internacional del Etnomatemática. E-mail: carolinatamayo@ufmg.br. ORCID: 0000-0002-8478-7845

${ }^{2}$ Professora da Faculdade de Educação da Universidade de São Paulo (Brasil). Integrante do grupo de pesquisa interinstitucional inSURgir da Universidade Federal de Minas Gerais (Brasil). E-mail: michelat@usp.br. ORCID: 0000-0002-6298-1137
} 
Palabras Clave: Etnomatemática; Modernidade/Colonidade; Decolonialidad; Justicia Social; Racismo Estructural

\begin{abstract}
This article starts from the conception of a school in crisis that was aggravated in times of the pandemic caused by the "Covid-19" virus, and that it has created several challenges for Education (Mathematics) in Brazil, especially after the publication of the Guidelines for schools during the pandemic, published by the Ministry of Education, that authorized schools to develop teaching activities remotely. We start from some researchers who associate this crisis of school education with the exhaustion of the so-called Modernity/ Coloniality project, in order to think about an Education (Mathematics) that is not subjugated to it, but that, based on movements of political-epistemic disobedience, studies mathematical knowledge linked to other non-Western cosmogonies. For this, we will present speeches from children, youth and families, as well as images related to the problems and dilemmas of education in this pandemic, which were circulated through the media and electronic social networks after the beginning of social isolation and the closure of public schools in the city. Basic Education, seeking to tension and think in different ways the challenges and possibilities of Education (Mathematics) in times of a different life caused by the effects of the "Covid-19".
\end{abstract}

Key words: Ethnomathematics; Modernity/Coloniality; Decoloniality; Social justice. Structural Racism.

\title{
1. A CRISE DA INSTITUIÇÃO ESCOLAR: EFEITOS DA MODERNIDADE/COLONIALIDADE
}

Desde março de 2020 o Brasil e o mundo, com inúmeros esforços, trabalham para conter o aumento de pessoas contagiadas pelo coronavírus denominado "Covid-19”. Escolas públicas e particulares em temporalidades diferentes, segundo as normativas de cada um dos estados, fecharam suas portas e, tanto alunas, alunos, professoras, professores e demais funcionários receberam a indicação de ficar em casa seguindo a orientação da Organização Mundial da Saúde (OMS) do isolamento social. Diante dessa emergência sanitária, as redes de ensino brasileiras, públicas e particulares, tomaram a decisão de suspender as aulas presenciais entre 11 e 23 de março de 2020 e, foi indicado para aproximadamente 39 milhões de alunos da Educação Básica permanecerem em casa, aguardando novas medidas educacionais a respeito das atividades escolares.

Com a data da volta às aulas em aberto, pais e educadores, em início de abril, começaram a debater os rumos da educação considerando as Diretrizes para escolas durante a pandemia $^{3}$, publicadas em 18 de abril de 2020 pelo Conselho Nacional de Educação (CNE) em colaboração com o Ministério da Educação (MEC). Estas diretrizes autorizam as escolas da Educação Básica e instituições de Ensino Superior para que durante a pandemia do coronavírus substituam o ensino presencial por aulas que utilizem meios e Tecnologias de Informação e Comunicação. Além do mais, com a publicação no Diário Oficial da Medida Provisória No 934 de $1^{\circ}$ de abril de 2020, o governo esclareceu que as

\footnotetext{
${ }^{3}$ Disponíveis em: http://portal.mec.gov.br/component/content/article?id=89051
} 
Tamayo, C. \& Tuchapesk, M. (2020). Desafios e possibilidades para a Educação (Matemática) em tempos de "Covid-19" numa escola em crise. Revista Latinoamericana de Etnomatemática, 13(1), 29-48. DOI: $10.22267 /$ relatem.20131.39

800 horas da Educação Infantil, do Ensino Fundamental e do Ensino Médio poderiam ser distribuídas em um período diferente dos 200 dias letivos ${ }^{4}$.

A suspensão das aulas, sem dúvida foi uma das medidas mais importantes tomadas no início do aumento de infectados comunitários pelo "Covid-19” no Brasil. Uma medida importante para colaborar com o isolamento social entendendo que, a escola é um espaço onde o contato é inevitável. A suspensão não encontrou uma resposta coordenada a nível nacional, todos os estados adotaram atividades remotas usando qual seja: plataformas virtuais, sites, Teleaulas e até por meio do WhatsApp. Já, nas redes municipais de ensino, não aconteceu o mesmo movimento, visto que, ao menos sete capitais não adotaram nenhuma atividade remota.

Professoras e professores, alunos e alunas, pesquisadores e pesquisadoras, de um dia para outro viram-se tendo que atuar diante de um contexto de excepcionalidade e diante das alternativas que passaram a ser adotadas, com o objetivo de reduzir o prejuízo educacional e garantir o ano letivo. Assim, entendemos que seja importante pensarmos a respeito dessas alternativas pedagógicas, como as medidas e diretrizes estabelecidas, visto que, por exemplo, não foram explicitadas possibilidades de flexibilização dos currículos escolares.

Neste contexto, vale a pena notar que, a escola, entendida como instituição do aparelho do Estado, já antes da pandemia enfrentava diversas problemáticas considerando a desigualdade social, os fatores históricos, políticos e econômicos do Brasil, que tornaramse ainda mais graves com a chegada do "Covid-19"; além do mais, os sujeitos participantes da escola viram-se obrigados a enfrentar a "crise da educação escolar" como já vinha sendo anunciada por autores como, Arendt (1988); Sacristán (1999); Cortesão (2001); Goméz (2001); Vorraber (2003); entre outros. Alguns destes estudiosos associam esta crise da educação escolar ao esgotamento do chamado projeto da Modernidade/Colonialidade e a sua impossibilidade de cumprir as promessas de "escolarizar o mundo", de uma "educação para todos(as)":

"[...] a primeira consequência disso seria uma compreensão bem clara de que a função da escola é ensinar às crianças como o mundo é, e não instruí-las na arte de viver. Dado que o mundo é velho, sempre mais que elas mesmas, a aprendizagem volta-se inevitavelmente para o passado, não importa o quanto a vida seja

\footnotetext{
${ }^{4}$ Disponível em: http://portal.mec.gov.br/component/content/article?id=87211

${ }^{5}$ Nos remitimos à crítica desenvolvida no documentário "Escolarizando o mundo: o último fardo do homem branco" disponível em: https://youtu.be/3Xux89-8MX4
} 
transcorrida no presente. [...] É impossível determinar mediante uma regra geral onde a linha limítrofe entre a infância e a condição adulta recai, em cada caso. Ela muda frequentemente, com respeito à idade de país para país, de uma civilização para outra e também de indivíduo para indivíduo. [...] Não se pode educar sem ao mesmo tempo ensinar; uma educação sem aprendizagem é vazia e, portanto, degenera, com muita facilidade, em retórica moral e emocional. É muito fácil, porém, ensinar sem educar, e pode-se aprender durante o dia todo sem por isso ser educado. (Arendt, 1988, p. 246-247).

Nesse sentido, entendemos como necessário e importante pensar outras práticas educacionais e de pesquisa na Educação (Matemática), considerando junto com Arendt que o "mundo é velho" e que, portanto, os sistemas escolares não podem continuar invisibilizando os efeitos da permanência da "matriz ou padrão colonial de poder" (Mignolo, 2008). Estes efeitos, vão desde o racismo estrutural até a invisibilização epistemológica, que segundo Quijano (2005), se escondem detrás da retórica da modernidade fundamentada na classificação dos sujeitos, que se dá com base em três linhas: raça, gênero e trabalho, e que dividiu o mundo entre os dominantes/superiores 'europeus' e os dominados/inferiores 'não-europeus'.

A "modernidade" é uma narrativa complexa, que propõe uma forma de se ver o mundo, cujo ponto de origem foi a Europa, uma história que constrói a civilização ocidental ao celebrar as suas conquistas enquanto esconde, ao mesmo tempo, o seu lado mais sombrio, a "colonialidade" (Mignolo, 2017), isto é, podemos dizer que não existe modernidade sem colonialidade, entendendo que a colonialidade é a continuação do colonialismo por outros meios. Segundo Dussel (1994), a modernidade foi gestada na Europa medieval em 1492- 500 anos antes da conquista de Abya YalalAmérica Latina:

1492, según nuestra tesis central, es la fecha del "nacimiento" de la Modernidad; aunque su gestación -como el feto- lleve un tiempo de crecimiento intrauterino. La Modernidad se originó en las ciudades europeas medievales, libres, centros de enorme creatividad. Pero "nació" cuando Europa pudo confrontarse con "el Otro" y controlarlo, vencerlo, violentarlo; cuando pudo definirse como un "ego" descubridor, conquistador, colonizador de la Alteridad constitutiva de la misma Modernidad. De todas maneras, ese Otro no fue "des-cubierto" como Otro, sino que fue "en-cubierto" como "lo Mismo" que Europa ya era desde siempre. De manera que 1492 será el momento del "nacimiento" de la Modernidad como concepto, el momento concreto del "origen" de un "mito" de violencia sacrificial muy particular y, al mismo tiempo, un proceso de "en-cubrimiento" de lo no europeo. (Dussel, 1994, p. 8-9).

Deste modo, a modernidade, como projeto civilizatório, se concretizou com a conquista, exploração e pilhagem da Abya Yala/América Latina, isto é, como explicita Grosfoguel (2008), com a chegada do homem 
Tamayo, C. \& Tuchapesk, M. (2020). Desafios e possibilidades para a Educação (Matemática) em tempos de "Covid-19" numa escola em crise. Revista Latinoamericana de Etnomatemática, 13(1), 29-48. DOI: $10.22267 /$ relatem.20131.39

heterossexual/branco/patriarcal/cristão/militar/capitalista europeu nas Américas se reproduziram e impuseram padrões hierárquicos globais já existentes. Assim, buscando modos e práticas que resistam a esses modelos instituídos, o Grupo Modernidade/Colonialidade, constituído no final dos anos 1990, formado por intelectuais latino-americanos situados em diversas universidades das Américas, propôs o "giro decolonial" (Maldonado-Torres, 2008), que consiste em um movimento de resistência teórico/prático e político/epistemológico, à lógica da Modernidade/Colonialidade.

Contudo, entendemos que o anterior poderia desdobrar-se nos debates sobre Educação (Matemática), tal como a provocação de ideias que favoreçam a "desobediência políticoepistêmica" ${ }^{6}$ na escola, na universidade e na pesquisa acadêmica, não para pensar uma Educação que ignore a Matemática difundida no projeto Modernidade/Colonialidade, mas para pensar uma educação que não se subjuga a ela e, que, por exemplo, também estude e difunde os conhecimentos matemáticos vinculados a outras cosmogonias ${ }^{7}$ não ocidentais, na medida que, invisibilizados por diversos efeitos, como o da racialização, foram excluídos dos sistemas escolares e universitários, tendo favorecido a manutenção da branquitude 8 como esse lugar onde o branco vê aos outros diferentes de sí, como inferiores.

Preocupadas com a produção desses caminhos parciais, que representam apenas parte de um todo, nos aproximamos de estudos como o da socióloga nigeriana, Oyèrónkẹ Oyěwùmí, que desenvolve um importante trabalho com o povo Yorùbá, discutindo questões a respeito da decolonialidade, questionando-a quanto ao fato desta ser estabelecida nas relações do saber dos povos que foram colonizados. Em seus estudos, a socióloga ressalta que as análises feitas pelos colonizadores são falsas leituras do povo Yorùbá, visto que, são baseadas em concepções ocidentais que não fazem sentido com a realidade dessa comunidade, que se organiza sem distinção de gênero e sem estrutura patriarcal. Inclusive, as pesquisas de Oyěwùmí tem contribuído nos estudos sobre gênero

\footnotetext{
${ }^{6}$ No sentido de Mignolo (2008).

${ }^{7}$ Entendemos a cosmogonia na perspectiva de Mircea Eliade (1972), que a entende como "o modelo exemplar de todos os tipos de "atos": não só porque o Cosmo é o arquétipo ideal de toda situação criadora e de toda criação mas também porque o Cosmo é uma obra divina, sendo, portanto, santificado em sua própria estrutura. [...]. "A prova de que o mito cosmogônico não é uma simples variante da espécie constituída pelo mito de origem está em que as cosmogonias, como acabamos de ver, servem de modelo para todos os tipos de "criações""' (p.31).

${ }^{8}$ Nos referimos a Cardoso (2010), para pensar o termo branquitude como "um lugar de privilégios simbólicos, subjetivos, objetivo, isto é, materiais palpáveis que colaboram para construção social e reprodução do preconceito racial, discriminação racial "injusta" e racismo" (p. 611).
} 
numa perspectiva africana, abrindo margem para questionar a crença de que todo passado sempre foi patriarcal.

Nesta mesma direção de resistência à invisibilização epistêmica produzida pela imposição unilateral de valores da Modernidade/Colonialidade, vale a pena ressaltar que em 2004 por iniciativa de Paulus Gerdes junto a outros pesquisadores africanos - se funda o "Southern African Ethnomathematics Study Group" (SAEmSG) na University of Zululand in Epamgeni (África do Sul) com o propósito de identificar colegas da região que estivessem interessados ou desenvolvendo pesquisas sobre Etnomatemática ${ }^{9}$.

Assim como estes pesquisadores na África, em latinoamérica (por exemplo: D’Ambrósio, 2007, 2019; Cuellar-Lemos, 2017; Baniwa, 2012; Correa Xakriabá, 2018; Bento dos Santos, 2019) têm levantado debates sobre os modos em que a Matemática eurocêntrica tem se colocado nos currículos escolares como única, neutra, universal, sendo efeito do modelo de escolarização moderna pautado como dispositivo útil ao projeto Modernidade/Colonialidade, que medeia subjetividades com base na distinção entre conhecimento cientificamente comprovado e aqueles conhecimentos relegados aos dogmas. Estes estudos, de alguma forma, procuram inverter a lógica colonial ao recompilar o conhecimento produzido fora dos centros hegemônicos de poder e escritos em outras línguas não-hegemônicas, que fazem referência a saberes produzidos, validados e legitimados no interior de culturas que foram e continuam sendo invisibilizadas nas relações de saber/poder que permeiam a escola, pois:

A Colonialidade do Saber nos revela, ainda, que, para além do legado de desigualdade e injustiça sociais profundos do colonialismo e do imperialismo, já assinalados pela teoria da dependência e outras, há um legado epistemológico do eurocentrismo que nos impede de compreender o mundo a partir do próprio mundo em que vivemos e das epistemes que lhes são próprias. Como nos disse Walter Mignolo, o fato de os gregos terem inventado o pensamento filosófico, não quer dizer que tenham inventado $\mathrm{O}$ Pensamento. O pensamento está em todos os lugares onde os diferentes povos e suas culturas se desenvolveram e, assim, são múltiplas as epistemes com seus muitos mundos de vida. Há, assim, uma diversidade epistêmica que comporta todo o patrimônio da humanidade acerca da vida, das águas, da terra, do fogo, do ar, dos homens. (Porto-Gonçalves, 2005, p.3).

\footnotetext{
9 Alguns desses pesquisadores são: Angola: Manuel Domingos Cadete; Botswana: Obusitswe Pitso; Mozambique: Paulus Gerdes, Abdulcarimo Ismael, Marcos Cherinda, José Castiano, Daniel Soares; Sul África: Oupa Mashile, Mogege Mosimege, Herbert Khuzwayo, Queeneth Mkabela; Zimbabwe: David Mtetwa. Informação disponibilizado pelo International Study Group on Ethnomathematics (ISGEm) no seguinte site: file:///C:/Users/W/AppData/Local/Temp/SAEmSG.htm
} 
Tamayo, C. \& Tuchapesk, M. (2020). Desafios e possibilidades para a Educação (Matemática) em tempos de "Covid-19" numa escola em crise. Revista Latinoamericana de Etnomatemática, 13(1), 29-48. DOI: $10.22267 /$ relatem.20131.39

A escola como instituição do aparelho de Estado não só reproduz essa herança, como também, está ancorada a políticas que serão definidas pelo imperativo jurídico da modernização, o que transformou a escola como espaço no qual disciplinariza-se não só o saber, mas também, o corpo (Veiga-Neto, 2008b), para isto "o comportamento da criança deverá ser regulamentado e vigiado, submetido à aquisição de conhecimentos, capacidades, hábitos, valores, modelos culturais e estilos de vida que lhe permitam assumir um papel produtivo na sociedade" (Castro-Gómez, 2005, p.85).

A escola enquanto instituição, ao operar com currículos disciplinarmente organizados, se constituiu como um importante instrumento na fabricação da Modernidade, pois "foi por intermédio dessa invenção que a escola se organizou e atuou, inventando novas formas de vida que romperam com os sentidos e usos medievais do espaço e do tempo" (VeigaNeto, 2002, p. 1). Deste modo, a instituição escolar tem como papel principal a promoção da escolarização universal e obrigatória, assim como, a disseminação da epistemologia ocidental, é por isto que, a “crise que se sente na educação é a manifestação de uma crise maior, mais ampla: a grande crise de esgotamento de valores, das formas de pensar e estar no mundo que foram constituídas na modernidade" (Veiga-Neto, 2008a, p.1).

Enfrentar a chamada "crise da educação escolar" que, como apontamos, antecede aos problemas e desafios derivados do fechamento das escolas públicas e particulares, como efeito da pandemia provocada pelo "Covid-19", pode ser ainda mais complexo quando observamos as propostas de ensino estabelecidas, especialmente nas escolas públicas do estado de São Paulo, a partir da promoção específica do ensino remoto ${ }^{10}$ na Educação Básica.

Deste modo, entendemos que a crise pode se aprofundar diante desta deliberação, uma vez que, pensar a educação escolar a partir especificamente do ensino remoto de Matemática implica, necessariamente, algumas condições mínimas para o desenvolvimento do trabalho dos professores, bem como a possibilidade de aprendizagem dos alunos. Portanto, achamos importante questionarmos o fato de que os estudos, no

\footnotetext{
${ }^{10}$ Buscando contribuir com a formação dos profissionais da Rede e ampliar a oferta aos alunos de uma educação mediada por tecnologia com o desenvolvimento do ensino remoto na Educação Básica, a Secretaria da Educação do Estado de São Paulo disponibilizou o Centro de Mídias da Educação de São Paulo (https://centrodemidiasp.educacao.sp.gov.br/o-que-e-o-centro-de-midias/). Neste espaço virtual podem ser encontrados conteúdos elaborados por especialistas e oferecidos por meio de tecnologias digitais, que serão transmitidos ao vivo a partir de estúdios de TV e pelo portal e aplicativos do CMSP. As aulas também podem ser acompanhadas, pelo canal digital da TV Educação e TV Univesp. Os conteúdos apresentados ficarão disponíveis para consulta de alunos, responsáveis e profissionais da Rede.
} 
caso, relacionados às especificidades para o trabalho com o ensino remoto, ainda estejam sendo considerados superficialmente. Tal como, quando ignoramos que muitos estudantes e educadores, principalmente, da rede de ensino público, não têm acesso à internet ou computador em casa e, ainda, que nem todos os professores e alunos sabem usar plataformas de ensino virtuais.

O anterior implica considerar, inclusive, a desigualdade social e econômica histórica que caracteriza o Brasil, visto que as principais medidas de prevenção para conter o "Covid19" não estão ao alcance de uma parte considerável da população que, por exemplo, encontra-se desempregada, realizando trabalhos informais e sem acesso à água potável e sabão - itens essenciais para manter a higiene e prevenir-se do vírus de acordo com a OMS.

Isto posto, apontamos alguns questionamentos que podem favorecer o movimento de ideias práticas e teóricas para enfrentarmos e/ou resistirmos aos desafios e possibilidades da Educação (Matemática) em tempos de "Covid-19" numa escola em crise, sendo eles: Como é possível oferecer uma educação não presencial quando nem todos terão os mesmos recursos para usufruí-la? Qual a pertinência de se manter o ensino de Matemática segundo os currículos estandarizados em tempos de "Covid-19”? Como pensar uma Educação (Matemática) a serviço da vida em tempos de pandemia?

\section{CRIANÇAS E FAMÍlIAS QUE FALAM PARA UMA ESCOLA EM CRISE EM TEMPOS DE UMA VIDA OUTRA PROVOCADA PELO “COVID-19”}

A seguir, apresentaremos falas de crianças, jovens e famílias, assim como imagens relacionadas aos problemas e dilemas da educação nesta pandemia, que colocaram-se em circulação pelas mídias e redes sociais eletrônicas após o início do isolamento social e do fechamento das escolas públicas da Educação Básica, procurando tensionar e pensar de modos outros os desafios e possibilidades da Educação (Matemática) em tempos de uma vida outra provocada pelos efeitos do "Covid-19".

Buscando praticar o exercício de construir um texto que movimentasse diversos tipos de jogos de linguagem ${ }^{11}$, no sentido wittgensteniano, entendemos que as falas e imagens que coletamos, de algum modo, nos afetaram e nos deram potência criativa para produzir uma

\footnotetext{
11 Afastado do desejo de apreender a essência da linguagem, Wittgenstein (2009, IF, §7) entende a "totalidade: da linguagem e das atividades com ela entrelaçadas, de "jogo de linguagem".
} 
Tamayo, C. \& Tuchapesk, M. (2020). Desafios e possibilidades para a Educação (Matemática) em tempos de "Covid-19" numa escola em crise. Revista Latinoamericana de Etnomatemática, 13(1), 29-48. DOI: $10.22267 /$ relatem.20131.39

escrita que tocasse a vida. Vidas relatadas em tempos de angústia e dúvidas, que na imanência busca provocar a construção de uma vida outra, partindo da concepção de que a vida projetada com base na Modernidade/Colonialidade nunca foi "normal".

Ao trazer imagens para compor está escrita, e não só falas textualizadas, queremos valorizar a concepção de que estas são tão importantes quanto outros jogos de linguagem, uma vez que, por si só, elas mobilizam e performam conhecimentos, saberes, sentidos e afetos, assim como a linguagem discursiva - no caso as falas textualizadas-, pois:

As imagens querem direitos iguais aos da linguagem e não simplesmente serem transformadas em linguagem. Elas não querem ser nem igualadas a uma "história das imagens", nem elevadas a uma "história da arte", mas sim serem consideradas como individualidades complexas ocupando posições de sujeito e identidade múltiplas. [...] $\mathrm{O}$ que as imagens querem, portanto, não é serem interpretadas, decodificadas, adoradas, rompidas, expostas ou desmistificadas por seus espectadores ou encantá-los. Elas podem nem mesmo desejar que comentadores bem-intencionados, que pensam que a humanidade é o maior elogio que se lhes pode oferecer, lhes outorgue subjetividade. Os desejos das imagens podem ser inumanos ou não-humanos, mais bem modelados pelas figuras de animais, máquinas, ou mesmo por imagens mais básicas - aquilo que Erasmus Darwin chamava de "amor das plantas". Portanto o que as imagens querem, em última instância, é simplesmente serem perguntadas sobre o que querem, tendo em conta que a resposta pode muito bem ser "nada". (Mitchell, 2017, p. 186-187).

Deste modo, ao nos propor construir um tecido composto pela interação ou não entre imagens e falas textualizadas, procuramos desenvolver um movimento de provocação em que, tanto uma como a outra, possuem a sua lógica própria sem estarem subordinadas entre si. Isto é, as imagens não necessitam de uma linguagem textual para se fazerem entender, não dependem de um princípio exterior a elas, enquanto produzidas e produtoras de sentidos dentro de formas de vida específicas (Wittgenstein, 2009).

\title{
2.1. Falas e imagens para uma escola em crise em tempos de uma vida outra provocada pelo "Covid-19"
}

\begin{abstract}
$\leftrightarrow$
"Oi professora, tudo bem? [...] Sem você professora, eu não consigo aprender bem. A mãe não é igual você. Você tem as manias de "pro". A minha mãe não tem. Ela trabalha num restaurante, ela só tem mania de fazer comida. Desculpe incomodar agora, mas eu queria falar para senhora isso"12. [Áudio de aluno enviado para professora].
\end{abstract}

\footnotetext{
12 Áudio disponível em:

https://www.instagram.com/p/B_iCC4joiQ/?utm_source=ig_embed\&utm_campaign=embed_video_watc h_again
} 


\section{$\leftrightarrow$}

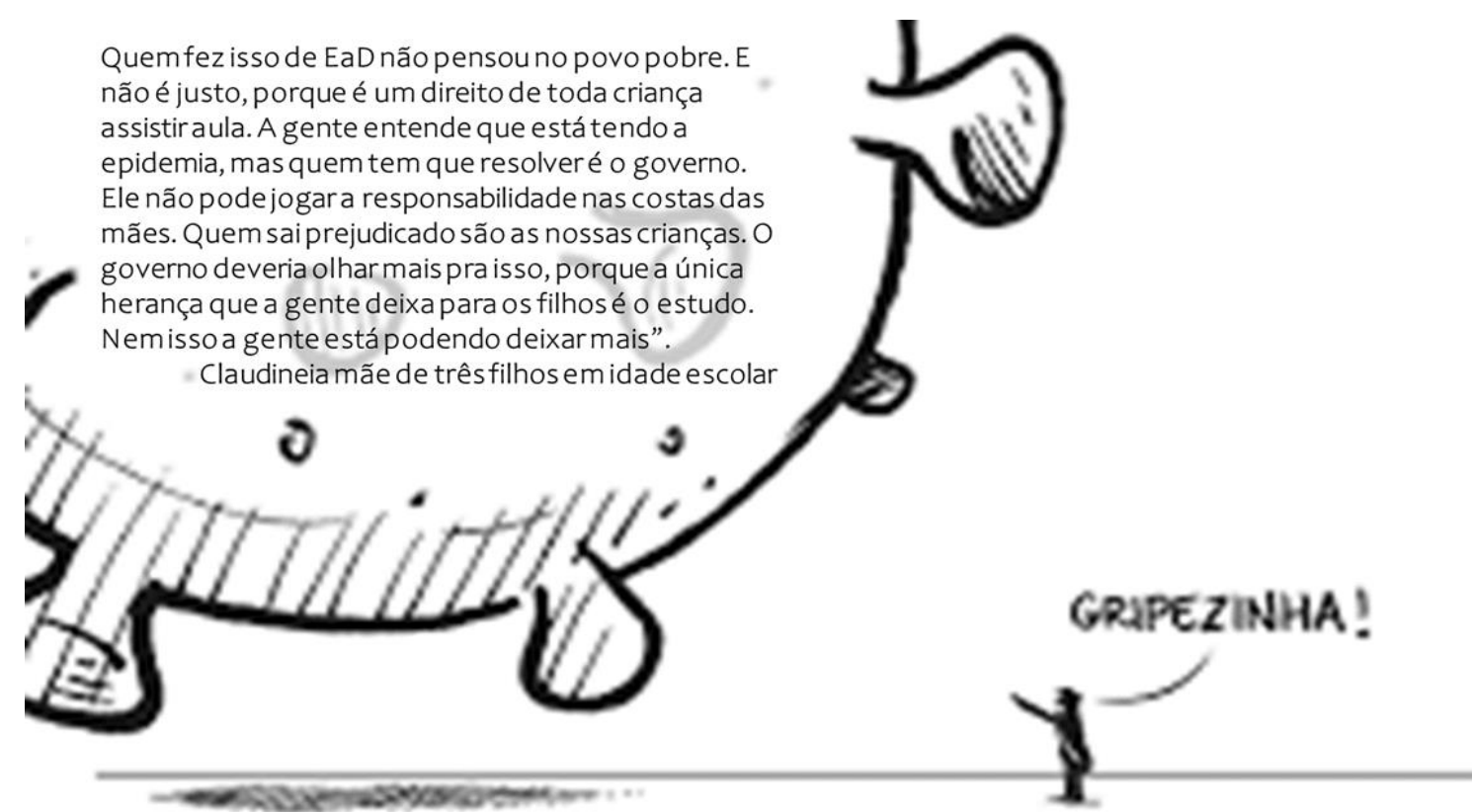

Fonte: imagem ${ }^{13}$.

Fonte: fala ${ }^{14}$.

$\leftrightarrow$

“A escola está de PARABÉNS!!! Acho que vai dar muito certo. As mães do grupo da classe do Alê compartilharam do mesmo sentimento! O Alê acordou cedo, não tãoooo cedo, rsss, mas às $8 \mathrm{~h} 30$ estava lá... ouvindo as aulas, falando com os professores... Fez todos os exercícios. Revisei e estava praticamente tudo certo. Ele enviou as tarefas e disse: 'Mãe assim vai ser muito legal estudar'. Muito obrigada por vocês terem sido tão ágeis diante desse caos que se instaurou sobre todos nós. Vai dar certo... já deu certo!". Veridiana Machado De Sá e Ferreira ${ }^{15}$.
"Sinceramente, eu estou achando bem ruim, pois a comunicação e a interação com os professores são bem difíceis, e é difícil acompanhar o que eles passam pela TV ou pelo computador. Esse método de ensino parece mais complicado de entender, e é ruim porque não temos como tirar dúvidas no momento em que elas surgem. Caso você não entenda algo, não é como no colégio, onde os professores repetem até você entender"16. Pedro Daniel.

\footnotetext{
${ }^{13}$ Disponível em: https://images.app.goo.gl/eWL9A3GxmEjgjNQT6

${ }^{14}$ Fala disponível em: https://appsindicato.org.br/a-distancia-do-ensino-conteudo-digital-nao-chega-aosalunos-da-periferia/

${ }^{15}$ Fala disponível em: http://www.jeanpiaget.g12.br/ensino-medio/familias-relatam-suas-experienciascom-ensino-remoto/

${ }^{16}$ Fala disponível em: https://www.brasildefato.com.br/2020/05/04/professores-pais-e-alunos-apontamdificuldades-e-limitacoes-no-ensino-a-distancia
} 


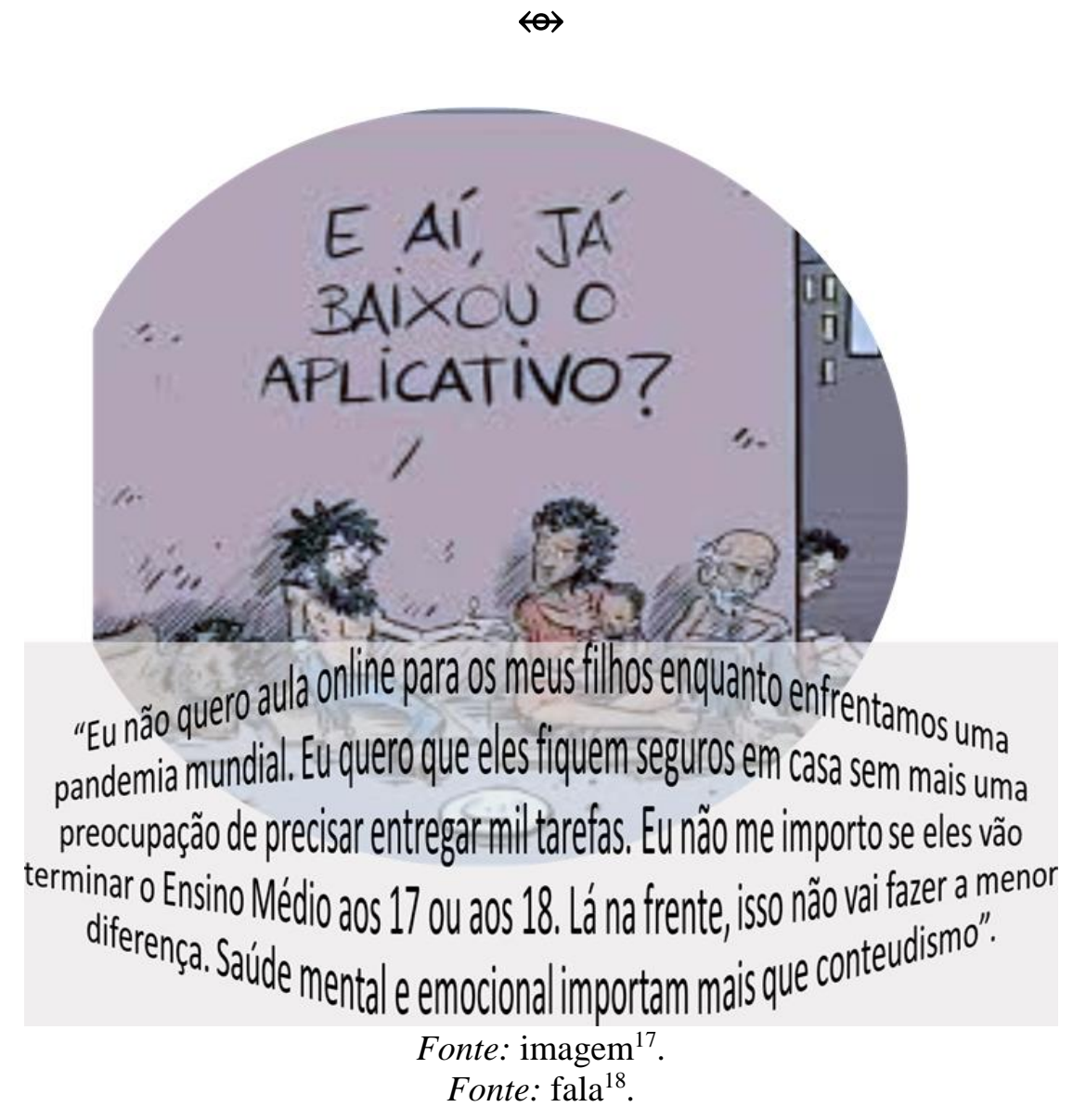

\begin{abstract}
$\leftrightarrow$
"O meu sinal não é wi-fi, então não consigo baixar os arquivos. Quase sempre os materiais chegam atrasados. Além disso, deixamos de ter aulas, ao vivo ou gravadas, em pleno ano de vestibular. A escola nos fornece uma série de PDFs e vídeos que não são dos nossos professores [...] É como se tivéssemos perdido o vínculo com a nossa formação, com os estudos". Pablo Henrique Saldanha, morador de Caxias, favela da Vila São Luiz (Rio de Janeiro) ${ }^{19}$.

“Às vezes, a internet da associação de moradores falha e perco a continuidade das leituras. Às vezes, a velocidade não é suficiente para assistir a uma videoaula. Sigo estudando por materiais aleatórios, mas com dificuldades. Tenho tentado não parar, mas às vezes bate a desmotivação. Não ter internet nesse momento em que não podemos sair de casa é um obstáculo enorme". Luiz Menezes, vestibulando morador da Maré $\left(\right.$ Rio de Janeiro) ${ }^{20}$.

\footnotetext{
${ }^{17}$ Disponível em: https://images.app.goo.gl/48VAzhx88t3pXkMV8

${ }^{18}$ Fala disponível em: https://www.brasildefato.com.br/2020/05/04/professores-pais-e-alunos-apontamdificuldades-e-limitacoes-no-ensino-a-distancia

19 Fala disponível em: https://educacao.uol.com.br/noticias/2020/04/28/sem-internet-estudantes-defavelas-sofrem-com-preparacao-online-para-enem.htm?cmpid=copiaecola

20 Fala disponível em: https://educacao.uol.com.br/noticias/2020/04/28/sem-internet-estudantes-defavelas-sofrem-com-preparacao-online-para-enem.htm?cmpid=copiaecola
} 


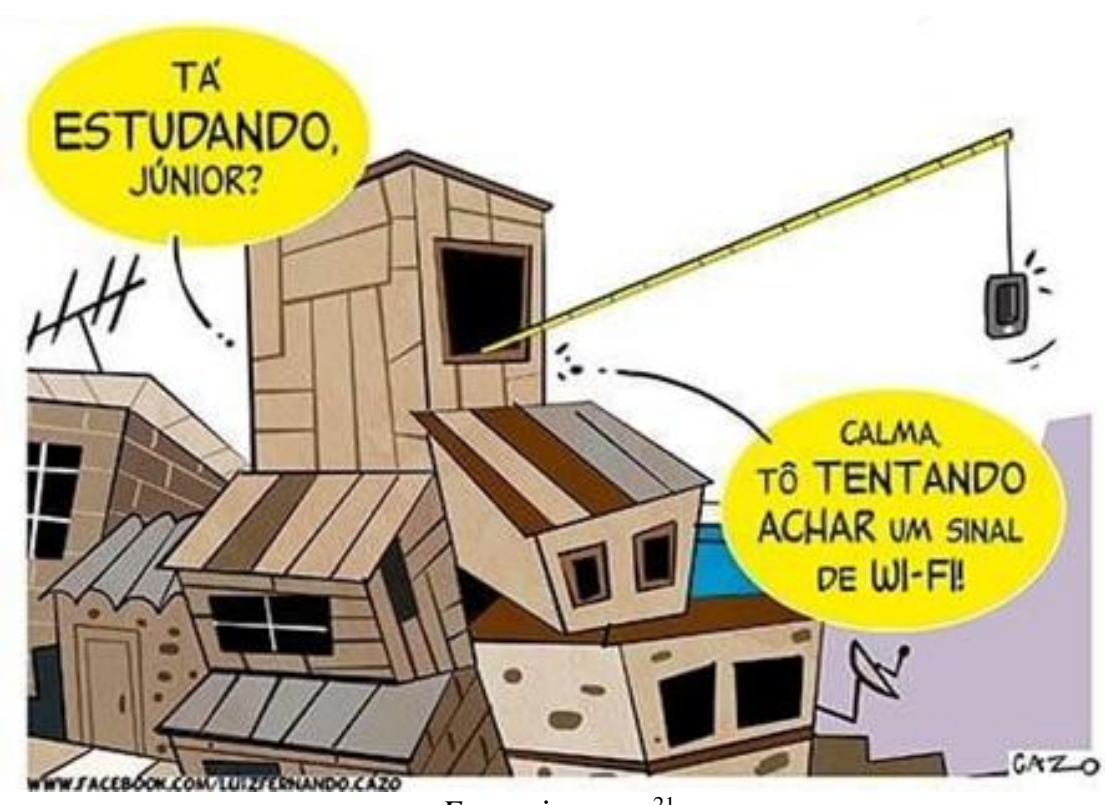

Fonte: imagem ${ }^{21}$

$\leftrightarrow$

"O processo de início das aulas online "foi péssimo". "Deixei acumular 45 atividades de diversas disciplinas, em duas semanas. Não consigo, não tenho esse tempo livre, estou no meu ritmo de trabalho normal desde que tudo começou". Sara Salenave, mãe de duas crianças, uma de 6 anos e outra de 4 anos. ${ }^{22}$

$\leftrightarrow$

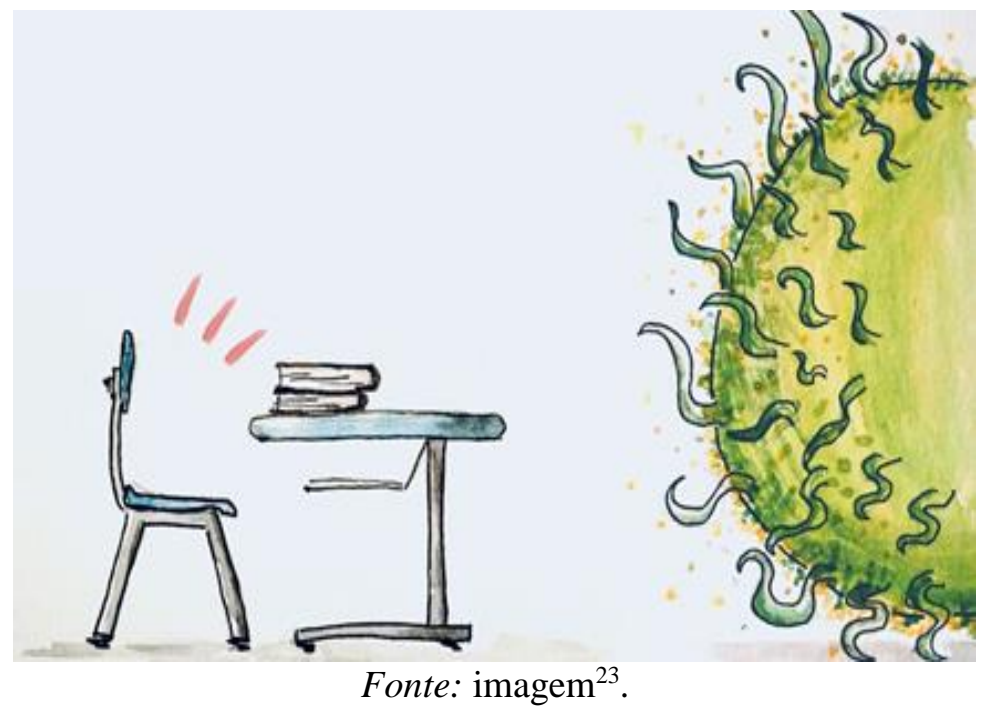

\footnotetext{
21 Publicado em 07/05/2020 por Luiz Fernando Cazo. Disponível em: https://www.humorpolitico.com.br/author/cazo/

22 Fala disponível em: https://agenciabrasil.ebc.com.br/educacao/noticia/2020-04/pais-e-educadoresdiscutem-estrategia-de-ensino-infantil-em-casa

$23 \mathrm{O}$ novo coronavírus esvazia escolas e universidades Foto: Fabio Campos. Fonte: https://epoca.globo.com/como-estudar-em-tempos-de-pandemia-24318249
} 
Tamayo, C. \& Tuchapesk, M. (2020). Desafios e possibilidades para a Educação (Matemática) em tempos de "Covid-19" numa escola em crise. Revista Latinoamericana de Etnomatemática, 13(1), 29-48. DOI: $10.22267 /$ relatem.20131.39

$\leftrightarrow$

"Eles têm tentado nos convencer de que nós somos protagonistas nesse processo. Tem muita risada, piada e meme a esse respeito, inclusive. A gente é protagonista, mas eles dizem que você pode mexer nos conteúdos que a sede está mandando, mas dizem que não deve mexer muito, não é aconselhável. Dizem que você pode tirar as atividades, mas aí o aconselhável depois é não tirar. Então, é uma coisa muito complicada. Nunca na vida quis trabalhar com EAD, e agora estou metida nessa encrenca". Professora Elisa. ${ }^{24}$

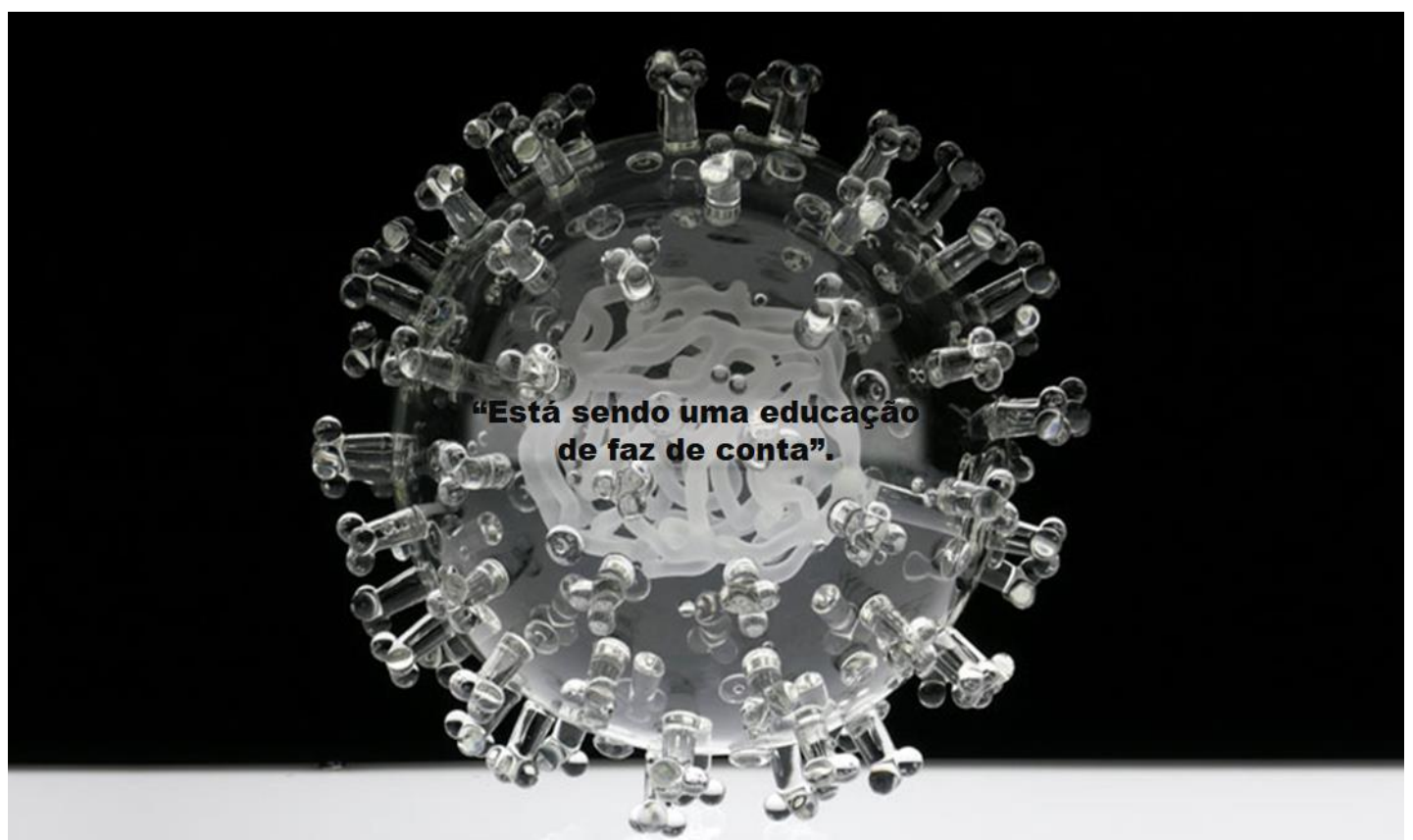

Fonte: imagem ${ }^{25}$. Fonte: fala ${ }^{26}$.

\section{DESLOCAMENTOS EM TEMPOS DE “COVID-19" PARA A EDUCAÇÃO (MATEMÁTICA) NUMA ESCOLA EM CRISE.}

No movimento junto às falas de crianças, jovens e pais, assim como, das imagens e o seu poder performativo, percebemos alguns desdobramentos importantes que gostaríamos de colocar em termos de desafios e possibilidades que a Educação (Matemática) enfrenta para continuar a construir práticas pedagógicas que configurem uma escola outra. E ao

\footnotetext{
${ }^{24}$ Fala disponível em: https://www.brasildefato.com.br/2020/05/04/professores-pais-e-alunos-apontamdificuldades-e-limitacoes-no-ensino-a-distancia

${ }^{25}$ Disponível em: https://www.lukejerram.com/glass/gallery/coronavirus-covid-19

${ }^{26}$ Graciella Fell, de Santa Catarina (Brasil). Fala disponível em:

https://g1.globo.com/educacao/noticia/2020/05/21/estudantes-pais-e-professores-narram-apagao-doensino-publico-na-pandemia-em-7-estados-e-no-df-atividade-remota-nao-vai-contar-para-o-anoletivo.ghtml
} 
mesmo tempo apresentar os efeitos que isto tem para pensarmos a respeito do ensino de Matemática em tempos de pandemia, procurando provocar algumas discussões diante de certas práticas como o "aprender com" e o "aprender como" (Cammarota \& Clareto, 2012; Gallo, 2012; Tamayo \& Da Silva, 2018), as matemáticas ${ }^{27}$ na escola e, principalmente, os processos de lutas e resistências (Foucault, 2009; Da Silva, 2014) dos professores diante de normas e regras estabelecidas como, por exemplo, a predominância do currículo escolar da Matemática acadêmica.

Neste sentido, nosso propósito não é estabelecer o que está certo ou errado sobre as formas como as políticas educacionais estão lidando com a agudização da crise da escola, mas sim, abrir debates junto às práticas e teorias movimentadas na Educação (Matemática), como, por exemplo, pensar que tal agudização é um sintoma do fracasso do projeto Modernidade/Colonialidade instaurado de forma violenta na Abya Yala.

De acordo com a UNICEF (2012), a discriminação racial é uma das principais barreiras que os jovens brasileiros enfrentam para ter garantido seu direito à educação. Do total de excluídos da escola, a maioria é negra e parda. E a discriminação não se manifesta apenas na dificuldade de acesso, mas também na continuidade da vida escolar. A diferença entre a média de anos de estudo da população negra e a média de anos de estudo da população branca, que se somam às mais altas taxas de repetência e abandono entre jovens negros parece evidenciar que a discriminação racial interfere de forma significativa no rendimento escolar dos alunos do Ensino Fundamental e Médio. (Oliveira, 2020, p. 14).

Nesse sentido, a formação de relações sociais fundadas nessa ideia, redefiniu na Abya Yala outras raças e identidades raciais que foram estabelecidas como instrumentos de classificação social da população em prol do mantenimento de privilégios sociais, políticos e econômicos das elites colonizadoras, sendo que "a ideia de raça foi uma maneira de outorgar legitimidade às relações de dominação impostas pela conquista" (Quijano, 2005, p. 117) e que tem permanecido até hoje.

Esta permanência, como já dissemos, também interferiu no papel da escola como instrumento da Modernidade/Colonialidade e como instituição do aparelho do Estado. Nesse sentido, e considerando os efeitos das falas e imagens aqui apresentadas, apontamos como um dos desafios da Educação (Matemática) a necessidade de se pensar modos e condutas outras que contribuam para a construção de mecanismos de resistências diante das políticas educacionais que, no caso do Brasil, procuram manter a estrutura de

\footnotetext{
${ }^{27}$ No sentido proposto por Tamayo \& Da Silva (2018).
} 
Tamayo, C. \& Tuchapesk, M. (2020). Desafios e possibilidades para a Educação (Matemática) em tempos de "Covid-19" numa escola em crise. Revista Latinoamericana de Etnomatemática, 13(1), 29-48. DOI: $10.22267 /$ relatem.20131.39

uma escola que entendemos, já estava em crise e, portanto, favorece a continuidade da herança dos privilégios das elites, privilégios racializados.

Antes de tudo, quero nos lembrar, que bem-aventurados os que choram. Pode parecer estranho, mas espero que não nos mexamos deste lugar de luto muito rápido. É necessário lamentar como deveria ser lamentado. Ouvi alguém dizer que este país [Estados Unidos] ainda não aprendeu a chorar pelos negros, porque tentamos colocar um curativo, tentamos curar as coisas com muita leveza. Não quero que convertamos estes protestos em desfiles. Em segundo lugar, eu gostaria de dizer aos que estão no congresso deste país que a pandemia só tem exposto duas feridas da América a ferida do racismo e da pobreza e são ameaças para a seguridade nacional. O fato é que, até esta data, qualquer fractura, inclusive, o orçamento nacional, o projeto de lei de heróis, não estão sendo feitos desde os pobres, não estão abordando o problema da raça. Necessitamos regressar e consertar isto, se queremos falar sério com o mundo no meio de uma pandemia, como é que não pode-se mudar o sistema de saúde? Isto me deixa de queixo caído, especialmente quando você conhece pessoas que estão morrendo. Pode ser que antes disso [antes da pandemia] não tenha sido possível colocar dinheiro na saúde, mas, certamente agora, depois da doação de 2 até 3 bilhões de dólares à corporações particulares, você [o Estrado] pode-se permitir a mudança. Finalmente, estamos chamando a uma marcha moral massiva, em 20 de junho de forma virtual, de pessoas brancas, negras, jovens, velhas, homossexuais, heterossexuais, transsexuais, latinos, asiáticos, nativos para que organizem para lidar com o racismo sistêmico, a pobreza sistêmica, a devastação ecológica, a negação de assistência sanitária, a economia de guerra e, assumir a existência falsa da narrativa moral, nacionalista religiosa [...] temos que sufocar todas estas coisas que sufocaram a George ${ }^{28}$ [...] quando dizemos "não posso respirar". [...] Se você soubesse que em 48 horas terá seu último suspiro, seja pelo 'Covid-19', ou se fosse vítima de alguém que põe o joelho no seu pescoço. Se você soubesse que tem 48 horas de respiração, para que usaria seu último suspiro? O que faria? Em que tipo de mundo você gostaria viver? Com que tipo de justiça? Com qual tipo de atendimento médico? Que luta faria contra o racismo? Poderíamos viver 48 anos, mas agora é importante que o último suspiro que saiu de George esteja entre em nós, e que todo suspiro das pessoas que morreram e que não deveriam ter morrido conectados aos respiradores, esteja entre nós para nos dizer que devemos dar mais vida a essa democracia, porque todo protesto que vemos é a justiça tentando respirar. Proteção igual para todos nos termos da lei, tentando respirar. Proteção da defesa comum, tentando respirar. A promoção do bem-estar geral, tentando respirar. O estabelecimento da justiça está apenas tentando respirar e, nós temos que ajudar". Ministro negro e Político ativista William J. Barber II (2020) ${ }^{29}$.

Isto posto, reforçamos que para surgirem práticas de resistências e lutas, neste caso, nas escolas, apontamos fortemente a importância de propormos, na formação inicial e

\footnotetext{
${ }^{28}$ George Perry Floyd Jr foi um homem afro-americano assassinado em Minneapolis no dia 25 de maio de 2020, estrangulado por um policial branco que ajoelhou-se em seu pescoço durante uma abordagem por supostamente usar uma nota falsificada de vinte dólares em um supermercado. Após sua morte, protestos contra o racismo rapidamente começaram a acontecer nos Estados Unidos e no mundo.

${ }^{29}$ Fala do Bispo William J. Barber II no programa especial de televisão intitulado "Where Do We Go From Here?" de OWN Channel em colaboração com Discovery Chanel e outros 18 canais de televisão americanos. Este programa, apresentado por Oprah Winfrey, ocorreu na sequência do assassinato de George Floyd e os protestos que se seguiram em todo Estados Unidos e o mundo desde então contra o racismo sistêmico e a brutalidade policial. Disponível em: https://www.youtube.com/watch?v=1jy6LpivqIM
} 
continuada dos professores, estudos teóricos e discussões práticas relacionadas ao exercício da autonomia do sujeito de acordo com Foucault (2005, 2006, 2007, 2010). Uma vez que, para este autor, o sujeito autônomo é aquele que se controla em todos os aspectos, se cuida integralmente, se autogoverna. "A autonomia está dentro do sujeito, ela age como o controle do fora, controle das questões: Quais forças/subjetivações aceito? Quais rejeito? Portanto, pessoas autônomas vão resistir o tempo todo!" (Souza \& Da Silva, 2015, p. 1313).

Neste sentido, consideramos que a falta do exercício da autonomia do professor implica a ausência ou menor possibilidade de práticas de resistências e questionamentos diante do projeto de escolarização moderno que impulsiona a manutenção de um ensino disciplinar e disciplinador (Veiga-Neto, 2008b) em tempos de uma pandemia mundial. Neste caso, sem a prática da autonomia, o professor deixa de questionar e resistir às imposições estabelecidas, por exemplo, pelas políticas educacionais, como as Diretrizes para escolas durante a pandemia e, portanto, deixa de lutar por oferecer uma educação não presencial com melhores condições de trabalho, bem como a promoção de um ensino e aprendizagem de matemáticas, no plural, para todos os alunos e todas as alunas. Como já apresentamos, nem todos e todas terão os mesmos recursos econômicos e sociais para usufruí-la, inclusive, quando sabemos que no Brasil cerca de 13,8 milhões de pessoas vivem na pobreza extrema.

É preciso pensar que durante esta pandemia crianças e jovens continuam experimentando o mundo e formando-se com base nos diferentes modos de vida. Não conseguimos quantificar especificamente quantos estão em isolamento social adequado, por exemplo, resguardados nas suas casas e, quantos mantém (ou tentam manter, talvez agora até com mais dificuldades) sua rotina diária como antes da pandemia. Inclusive, ainda não atingimos o "pico" de infectados por "Covid-19". Contudo, é sabido que existem diferentes modos de vida percorrendo essa pandemia e, estas diferenças sociais, econômicas e culturais precisam ser consideradas nas atribuições das políticas públicas, neste caso, especificamente, nas políticas públicas educacionais, evitando o aumento da desigualdade do acesso à educação no Brasil. 
Tamayo, C. \& Tuchapesk, M. (2020). Desafios e possibilidades para a Educação (Matemática) em tempos de "Covid-19" numa escola em crise. Revista Latinoamericana de Etnomatemática, 13(1), 29-48. DOI: $10.22267 /$ relatem.20131.39

Mesmo porque, diante das diferentes realidades e, sabendo que, aproximadamente ${ }^{30} 82 \%$ do total de alunos matriculados em escolas são da rede pública e $19 \%$ são de escolas privadas, os professores, as crianças, os jovens e as famílias, que encontram-se na possibilidade de permanecer horas e horas na frente das telas de computadores, smartphones e outros instrumentos tecnológicos com acesso à internet, na condição de acessar às aulas remotas, tornam-se corpos submetidos a processos formativos direcionados pelos interesses do Estado, ou pelas massas acríticas.

E, é neste último contexto que também se desvanece a possibilidade de reinventar a escola com base em práticas educacionais que mobilizem, por exemplo, o uso do "tempo livre", no sentido de Carvalho e Gallo (2017), um tempo do qual o sujeito pode dispor conforme seus interesses próprios, e que é absolutamente necessário para sua constituição subjetiva. Inclusive, talvez seja neste "tempo livre" que podemos mobilizar conhecimentos matemáticos que só possuem sentido na experiência com 'o acaso' que se manifesta na própria vida com base, neste caso, num vírus que ainda não consegue ser controlado.

Assim, entendemos que estas ideias podem permitir encaminhamentos, pensamentos que movimentam as perguntas sugeridas no início do texto 'qual a pertinência de se manter o ensino de Matemática segundo os currículos estandarizados em tempos de "Covid19”?' e “pensar uma Educação (Matemática) a serviço da vida em tempos de pandemia?" no sentido de desconstruir e repensar não só o currículo escolar hegemônico, bem como, o projeto Modernidade/Colonialidade ao dialogar com os conhecimentos subalternos que vêm sendo reivindicados pelos movimentos negros e indígenas e quilombolas e feministas e decoloniais e ... (Oyewùmí, 2012; Cuellar-Lemos, 2017; Baniwa, 2012; Correa Xakriabá, 2018) que através de projetos antirracistas e de transformação social estão espalhando nas escolas outros tipos de conhecimentos matemáticos, vinculados a outras práticas sociais, políticas, com base em outro poder social e estatal e, enfim, outro tipo de sociedade.

Nestes momentos de fragilidade não só da vida humana e não humana, senão também social, política e econômica que o mundo enfrenta, nos aderimos ao movimento evocado pelo Ministro norte americano negro e político ativista William J. Barber II, para que pessoas brancas, negras, homossexuais, heterossexuais, transsexuais, latinos, asiáticos,

\footnotetext{
${ }^{30}$ Segundo o Censo da Educação Básica de 2019 publicado em 2020 pelo Instituto Nacional de Estudos e Pesquisas Educacionais Anísio Teixeira (Inep).
} 
povos originários que, na potência do encontro com o outro, ocorram possibilidades de produzir um comum, que resiste ao racismo sistêmico, a pobreza sistêmica, a devastação ecológica, a negação de assistência sanitária, a economia de guerra, bem como, se contrapõe a falsa narrativa moral nacionalista religiosa.

Aqui, a resistência é contra um modo de vida disseminado como efeito da Modernidade/Colonialidade, um modo de vida que aniquila a diferença, um modo de vida que não faz circular práticas educacionais que potencializam a vida. Isto demarca um desafio: a construção de uma Educação (Matemática) que esteja ao serviço da vida e não a vida ao serviço da Educação (Matemática).

\section{REFERENCIAS}

Arendt, H. (1988). Entre o passado e o futuro. Tradução Mauro W. Barbosa de Almeida. São Paulo: Ed. Perspectiva. Brasil.

Baniwa, G. (2012). Educação para manejo e domesticação do mundo: entre a escola ideal e a escola real. Os dilemas da educação escolar indígena no Alto Rio Negro. Tese de doutorado, Universidade de Brasília.

Bento dos Santos, L. (2019). Bens Culturais afro-brasileiros: o ofício de mulheres negras trançadeiras em debate. Em Revista Eixo, v. 8 (2), p.126-137.

Cardoso, L. (2010). Branquitude acrítica e crítica: a supremacia racial e o branco antiracista. Revista Latinoamericana de Ciencias Sociales, Niñez y Juventud. 8 (1) pp.607-630.

Cammarota, G., \& Clareto, S. (2012). A cognição em questão: invenção, aprendizagem e Educação Matemática. Práxis Educativa, Ponta Grossa, 7(2), pp. 585-602.

Castro-Gómez, S. (2005). Ciências sociais, violência epistêmica e o problema da invenção do outro. En Lander, E. (Edits.), A colonialidade do saber: eurocentrismo e ciências sociais. Perspectivas latinoamericanas. Colección Sur Sur. CLACSO, Ciudad Autónoma de Buenos Aires, Argentina.

Carvalho, A. \& Gallo, S. (2017) Defender a escola do dispositivo pedagógico: o lugar do experimentum schola e na busca de outro equipamento coletivo. ETD-Educação Temática Digital Campinas, 19 (4) pp. 622-641.

Correa, C. (2018). Barro, o Genipapo e o Giz no fazer epistemológico de Autoria Xakriabá: reativação da memória por uma educação territorializada. Dissertação de Mestrado. Universidade de Brasília.

Cortesão, L. (2001). Guliver entre gigantes: na tensão entre estrutura e agência, que significados para a educação? En J. Correia, L. Cortesão, \& S. Stoer. (Edits.), Transnacionalização da Educação: da Crise da Educação à "Educação em Crise”. Porto: Afrontamento.

Cuéllar-Lemos, R. N. (2017). Nabba nana gala burbaba nanaedi igala odurdagge gunadule durdagedi nega gine: igal dummadi maidi sabbimala soganergwa naggulemaladi [La pedagogía de la Madre Tierra en una escuela indígena 
Gunadule: un estudio sobre la sabiduría de seis plantas de protección]. Master's Dissertation - Facultad de Educación, Universidad de Antioquia, Medellín.

D’Ambrosio, U. (2007) Etnomatemática: Elo Entre as Tradições e a Modernidade. Autêntica; Edição.

D’Ambrosio, U. (2019). O programa Etnomatemática e a crise da civilização. Hipátia 25, 4 (1). Recuperado de: https://ojs.ifsp.edu.br/index.php/hipatia/article/view/1087

Dussel, E. (1994). 1492: el encubrimiento del otro: hacia el origen del mito de la modernidad. UMSA. Facultad de Humanidades y Ciencias de la Educación. Plural Editores, La Paz.

Eliade, M. (1972). Mito e Realidade. Tradução Pola Civelli. 1. ed. São Paulo: Editora Perspectiva S.A.

Foucault, M. (2005). História da Sexualidade 3: o cuidado de si. Tradução de Maria Thereza da Costa Albuquerque. 8 ed Rio de Janeiro: Edições Graal.

Foucault, M. (2006). História da Sexualidade 1: a vontade de saber. Tradução de Maria Thereza da Costa Albuquerque e J. A. Guilhon Albuquerque. 17. ed. Rio de Janeiro: Edições Graal.

Foucault, M. (2007). História da Sexualidade 2: o uso dos prazeres. Tradução de Maria Thereza da Costa Albuquerque. 12 ed. Rio de Janeiro: Edições Graal.

Foucault, M. (2009). Vigiar e Punir: nascimento da prisão. 36 ed. Tradução de Raquel Ramalhete. Petrópolis, RJ: Vozes.

Foucault, M. (2010). A hermenêutica do sujeito. 3 ed. São Paulo: WMF Martins Fontes.

Gallo, S. (2012). As múltiplas dimensões do aprender... En anais do Congresso de Educação Básica: aprendizagem e Currículo. 2012. Disponível em: <http://www.pmf.sc.gov.br/arquivos/arquivos/pdf/13_02_2012_10.54.50.a0ac3b 8a140676ef8ae0dbf32e662762.pdf>

Gómez, A. (2001). A Cultura Escolar na Sociedade Neoliberal. Porto Alegre: Artmed.

Grosfoguel, R. (2008). Transmodernity, border thinking and global coloniality. Revista Crítica de Ciências Sociais. Recuperado em: https://www.eurozine.com/journals/revista-critica-de-ciencias-sociais/

Instituto Nacional de Estudos e Pesquisas Educacionais Anísio Teixeira (Inep). Censo da Educação Básica 2019: notas estatísticas. Brasília.

Maldonado-Torres, N. (2008). La descolonización y el giro des-colonial. Revista Tabula Rasa, 8, pp. 61-72.

Mitchell, W. (2017). O que as imagens realmente querem? Em Alloa E. (org). (2017), Pensar a imagem. Edt. Autêntica: Belo Horizonte.

Mignolo, W. (2008). Desobediência epistêmica: a opção descolonial e o significado de identidade em política. Cadernos de Letras da UFF, 34, pp. 287-324.

Mignolo, W. (2017). Colonialidade o lado mais escuro da modernidade. Revista brasileira de ciências sociais, 32 (94) pp. 1-18. 
Oliveira, L. (2020). Opção decolonial e antirracismo na educação em tempos neofascistas. En Revista da Associação Brasileira de Pesquisadores/as Negros/as (ABPN), [S.1.], 12(32) pp. 11-29, maio 2020. ISSN 2177-2770.

Oyewùmí, O. (2012). Beyond Gendercentric Models: Restoring Motherhood to Yoruba Discourses of Art and Aesthetics. En Creary, N. (Edits.), African intellectuals and decolonization. Ohio: Ohio University Press.

Porto-Gonçalves, C. (2005). Apresentação da edição em português do livro: A colonialidade do saber: eurocentrismo e ciências sociais. Perspectivas latinoamericanas. En Lander, E. (Edits.), A colonialidade do saber: eurocentrismo e ciências sociais. Perspectivas latinoamericanas. Colección Sur Sur, CLACSO, Ciudad Autónoma de Buenos Aires, Argentina.

Sacristán, J. (1999). Poderes Instáveis em Educação. Porto Alegre: ARTMED.

Silva, M. T. (2014). A Educação Matemática e o cuidado de si: possibilidades foucaultianas. Tese Doutorado em Educação Matemática. Universidade Estadual Paulista, Rio Claro.

Souza, A. \& Silva, M. (2015). Do conceito à prática da autonomia do professor de Matemática. En Bolema, Rio Claro (SP), 29(53). pp. 1309-1328.

Quijano, A. (2005). Colonialidade do poder, Eurocentrismo e América Latina. CLACSO, Consejo Latinoamericano de Ciencias Sociales Editorial/Editor: Buenos Aires.

Tamayo-Osorio, C. \& Da Silva, M. (2017). E se Nós Tivéssemos Escolas Mukanda Que Contassem Diversas Histórias Africanas Para Todo o Mundo? Em Educação Matemática em Revista. 23, (60), pp. 263-282.

Veiga-Neto, A. (2002). De geometrías, currículo e diferenças. Educação \& Sociedade, 23(79), 163-186. doi: 10.1590/S0101-73302002000300009

Veiga-Neto, A. (2008a). Entrevista: educação e crise são, respectivamente, causa e conseqüência uma da outra. Recuperado de: http://www.ihu.unisinos.br/entrevistas/11783-\%60educacao-e-crise-saoreciprocamente-causa-e-conseq\%C3\%BCencia-uma-da-outra\%60-entrevistaespecial-com-alfredo-veiga-neto

Veiga-Neto, A. (2008b). Crise da modernidade e inovações curriculares: da disciplina para o controle. Trajetórias e processos de ensinar e aprender: sujeitos, currículos e culturas. Memorias del XIV ENDIPE, p. 35-58. Recuperado de: http://www.grupodec.net.br/wpcontent/uploads/2015/10/CrisedaModernidadeAlf redo.pdf

Vorraber, M. (2003). A Escola tem futuro? Rio de Janeiro: DP\&A.

Wittgenstein, L. (2009). Philosophische Untersuchungen/Philosophical Investigations. Translated by Gertrude E.M. Anscombe, Peter M.S. Hacker, and Joachim Schulte. -Rev. 4th ed./by P.M.S. Hacker and Joachim Schulte.UK: Wiley-Blackwell Publishing Ltd. 